\title{
Bötzinger Expiratory-Augmenting Neurons and the Parafacial Respiratory Group
}

\author{
Michal G. Fortuna, Gavin H. West, Ruth L. Stornetta, and Patrice G. Guyenet \\ Department of Pharmacology, University of Virginia, Charlottesville, Virginia 22908
}

In neonatal rat brains in vitro, the rostral ventral respiratory column (rVRC) contains neurons that burst just before the phrenic nerve discharge (PND) and rebound after inspiration (pre-I neurons). These neurons, called parafacial respiratory group (pfRG), have been interpreted as a master inspiratory oscillator, an expiratory rhythm generator or simply as neonatal precursors of retrotrapezoid (RTN) chemoreceptor neurons. pfRG neurons have not been identified in adults, and their phenotype is unknown. Here, we confirm that the rVRC normally lacks pre-I neurons in adult anesthetized rats. However, we show that, during hypercapnic hypoxia, a population of rVRC expiratory-augmenting (E-AUG) neurons consistently develops a pre-I discharge. These cells reside in the Bötzinger region of the rVRC, they express glycine-transporter-2, and their axons arborize throughout the VRC. Hypoxia triggers an identical pre-I pattern in retroambigual expiratory bulbospinal neurons, but this pattern is not elicited in Bötzinger expiratory-decrementing neurons, Bötzinger inspiratory neurons, RTN neurons, and blood pressure-regulating neurons. In conclusion, under hypoxia in vivo, abdominal expiratory premotor neurons of adult rats develop a pre-I pattern reminiscent of that observed in neonate brainstems in vitro. In the rVRC of adult rats, pre-I cells include selected rhythmogenic neurons (glycinergic Bötzinger neurons) but not RTN chemoreceptors. We suggest that the pfRG may not be an independent rhythm generator but a heterogeneous collection of E-AUG neurons (glycinergic Bötzinger neurons, possibly facial motor and premotor neurons), the discharge of which becomes preinspiratory under specific experimental conditions resulting from, in part, a prolonged and intensified activity of postinspiratory neurons.

Key words: breathing; hypoxia; parafacial respiratory group; retrotrapezoid nucleus; central chemoreceptors; medulla oblongata

\section{Introduction}

En bloc preparations of the neonatal hindbrain (henceforth called the Suzue preparation) (Suzue, 1984) contain preinspiratory (pre-I) neurons that burst just before the phrenic nerve discharge (PND) and usually rebound at the end of inspiration (Arita et al.,1987; Onimaru et al., 1989; Bryant et al., 1993; Onimaru and Homma, 2003; Janczewski and Feldman, 2006; Onimaru et al., 2006a). Neurons with similar characteristics are found in neonate rats treated with ketamine and the opiate agonist fentanyl (Janczewski et al., 2002). These pre-I neurons, called the parafacial respiratory group (pfRG) (Onimaru and Homma, 2003), have not been identified in the adult.

The pfRG is generally viewed as a semi-independent respiratory oscillator (Feldman et al., 2003; Mellen et al., 2003; Onimaru and Homma, 2003; Feldman and Del Negro, 2006; Onimaru et al., 2006a). According to some investigators, the pfRG is a master inspiratory oscillator that is usually coupled to the pre-Bötzinger complex (the dominant inspiratory rhythm generator) (Onimaru and Homma, 2003; Onimaru et al., 2006b), whereas others assert that the pfRG is dedicated to expiratory rhythm and pattern generation (Feldman and Del Negro, 2006; Janczewski and

Received Sept. 20, 2007; revised Jan. 21, 2008; accepted Jan. 22, 2008.

This work was supported by National Institute of Health Grants HL28785 and HL074011 (P.G.G.).

Correspondence should be addressed to Dr. Patrice G. Guyenet, University of Virginia Health System, P.O. Box 800735, 1300 Jefferson Park Avenue, Charlottesville, VA 22908-0735. E-mail: pgg@virginia.edu. DOI:10.1523/JNEUROSCI.5595-07.2008

Copyright $\odot 2008$ Society for Neuroscience $\quad$ 0270-6474/08/282506-10\$15.00/0
Feldman, 2006; Onimaru et al., 2006b). The latter authors also surmise that some of the pre-I cells of the rostral ventral respiratory group (VRC) are excitatory neurons that are antecedent to bulbospinal expiratory premotor neurons (Janczewski et al., 2002). According to another theory (Feldman and Del Negro, 2006; Janczewski and Feldman, 2006), pfRG neurons could be the neonatal precursors of the chemosensitive neurons found in the retrotrapezoid nucleus (RTN) of the adult (Nattie and Li, 2000; Mulkey et al., 2004; Guyenet et al., 2005a). Finally, the pfRG may also generate respiratory-like oscillatory activity in subsets of facial motor neurons (Onimaru et al., 2006a). All these theories imply that the pfRG is a neonatal stage of development of the respiratory network. Their main weakness is that the pre-I neurons of the pfRG are still unidentified anatomically.

The Suzue preparation generates low-frequency decremental phrenic nerve bursts with characteristics reminiscent of the gasping response produced by severe hypoxia in adults in vivo (Paton et al., 2006). Therefore, we reasoned that the pre-I pattern might be observed in the rostral VRC of the adult rodent in vivo during severe hypoxia.

We show here that hypoxia in vivo changes the firing of expiratory-augmenting (E-AUG) respiratory interneurons (Bötzinger glycinergic neurons and abdominal premotor neurons) into a pre-I pattern reminiscent of that found in the Suzue preparation. Other types of respiratory neurons, including the RTN chemoreceptors, do not display the pre-I pattern under hypoxia. This work raises the possibility that the pfRG could be a 
functionally heterogeneous collection of E-AUG neurons with a pattern that becomes pre-I because of the specific environmental conditions present in the Suzue preparation.

\section{Materials and Methods}

The experiments were done in 20 halothane-anesthetized bilaterally vagotomized adult Sprague Dawley male rats $(270-350 \mathrm{~g})$. The work was conducted in accordance with National Institutes of Health and Institutional Animal Care and Use Guidelines. The Animal Research Committee of the University of Virginia approved all procedures and protocols.

In experiments exploring the rostral portion of the ventral respiratory column (Bötzinger region and RTN; 14 of 20 rats), we used a previously described physiological preparation without modification (Mulkey et al., 2004; Guyenet et al., 2005a). During surgery, the animals were maintained at $37.5^{\circ} \mathrm{C}$ and ventilated with $1.5-1.7 \%$ halothane administered in pure oxygen. End-expiratory $\mathrm{CO}_{2}$ was monitored with a capnometer. During recording, halothane was reduced to $\sim 1 \%$ and end-expiratory $\mathrm{CO}_{2}$ was adjusted to $9-10 \%$ by adding pure $\mathrm{CO}_{2}$ to the pure oxygen (tidal volume, $1-1.2 \mathrm{ml} / 100 \mathrm{~g}$; rate, $60-80 / \mathrm{min}$ ). Hypercapnia was used to approximate conditions present in neonate brainstem spinal cord preparations where extracellular $\mathrm{pH}$ is reportedly 6.9 or less (Brockhaus et al., 1993). Muscle relaxation was done with pancuronium. Hypercapnic hypoxia was produced by feeding a $5 \% \mathrm{O}_{2} / 95 \%$ nitrogen mixture instead of pure oxygen into the halothane vaporizer and maintaining the same addition of $\mathrm{CO}_{2}$ to the line before the ventilator intake. The duration of the hypoxia (60-120 s) was monitored by an oxygen electrode located at the intake of the ventilator.

The right PND was recorded and integrated as described previously (Mulkey et al., 2004; Guyenet et al., 2005a). Unit recordings were made using glass electrodes filled with biotinamide to label the recorded units by the juxtacellular method as described previously (Mulkey et al., 2004; Guyenet et al., 2005a). All analog data (end-expiratory $\mathrm{CO}_{2}$, PND, unit activity, action potential, $\mathrm{pO}_{2}$ of inhaled mixture) were stored on a microcomputer via a micro-1401 digitizer from Cambridge Electronic Design (Cambridge, UK) and were processed off-line using version 5 of the Spike 2 software (Cambridge Electronic Design) as described previously (Mulkey et al., 2004; Takakura et al., 2006; Moreira et al., 2007). Processing included action potential discrimination and measurement of neuronal discharge rate (averaged over consecutive $50 \mathrm{~ms}$ to $2 \mathrm{~s}$ intervals depending on the cell) and PND "integration" (iPND) consisting of full-wave rectification and smoothing $(\tau, 0.015 \mathrm{~s})$. Perievent histograms of neuronal discharge probability were made using PND onset as a trigger as described previously (Guyenet et al., 2005a).

The histological procedures required to identify the location of the biotinamide-labeled neurons have been described previously as well as the nonradioactive in situ hybridization method used to detect glycine transporter 2 (GLYT2) mRNA in neurons labeled with biotinamide (Schreihofer et al.,1999). The nonradioactive method used presently to detect vesicular glutamate transporter2 (VGLUT2) has also been described previously (Stornetta et al., 2003; Weston et al., 2004). Finally, the simultaneous detection of two mRNAs by in situ hybridization using FITC-labeled (in the present case for GLYT2) and digoxigenin-labeled (in the present case for VGLUT2) riboprobes was also performed with a previously published method (Stornetta et al., 2004).

Based on various descriptions of where the pfRG resides in the neonate (Janczewski et al., 2002; Onimaru and Homma, 2003; Feldman and Del Negro, 2006; Janczewski and Feldman, 2006; Onimaru et al., 2006a), we limited our electrophysiological explorations to the most ventral and rostral layers of the VRC between $300 \mu \mathrm{m}$ rostral and $300 \mu \mathrm{m}$ caudal to the posterior edge of the facial motor nucleus. The caudal and inferior edge of the facial motor nucleus were identified in every rat by antidromic mapping as described previously (Brown and Guyenet, 1985; Takakura et al., 2006). These landmarks were used in each rat to define the region of interest where unit recordings were selectively made. In the adult, the rostral half of this region $(0-300 \mu \mathrm{m}$ rostral to the caudal edge of the facial motor nucleus and $2-300 \mu \mathrm{m}$ below this nucleus) contains the bulk of the RTN chemoreceptors. The caudal half of the explored region belongs to the Bötzinger subdivision of the VRC (Alheid et al.,
2002). The anatomical nomenclature used is generally from Alheid et al. (2002), and stereotaxic coordinates are given in reference to the Paxinos and Watson atlas (1998).

In six rats, the head was flexed downward, and the atlanto-occipital membrane was opened to record from the retroambigual portion of the ventral respiratory column or caudal ventral respiratory group (cVRG) (Alheid et al., 2002). In these rats, a stimulating electrode was also inserted in the ventrolateral quadrant of the spinal cord at the third or fourth thoracic segment to test for axonal projections. Bulbospinal expiratory-augmenting neurons were found at a depth of $1.6-2.0 \mathrm{~mm}$ below the dorsal surface, $1.3-1.6 \mathrm{~mm}$ from the midline, and $0.5-0.9 \mathrm{~mm}$ caudal to the caudal end of the area postrema (calamus scriptorius) corresponding to the region of the retroambigual nucleus. Every expiratory-augmenting neuron recorded at this level $(n=27)$ had a spinal axon as evidenced by fixed latency antidromic activation (latency, $2.4 \pm 0.2 \mathrm{~ms}$; range, $1.3-6.4 \mathrm{~ms} ; n=27$ ) and a positive collision test. Antidromic activation could be obtained only from the contralateral side of the cord (stimulus duration, $0.1 \mathrm{~ms}$; intensity, $0.1-0.4 \mathrm{~mA}$ ), consistent with the known axonal trajectory of expiratory abdominal premotor neurons.

All results are expressed as means and SE. One-way ANOVA for repeated measures followed by the pairwise multiple comparison procedure (Student-Newman-Keuls method) was used to evaluate differences between groups when the assumptions of normality and equal variance were met. If they were not, the nonparametric Friedman repeatedmeasures ANOVA on ranks was used. Significance was set at $p<0.05$.

\section{Results}

Expiratory-augmenting Bötzinger neurons become preinspiratory under hypercapnic hypoxia

The caudal half of the region investigated $(0-300 \mu \mathrm{m}$ behind the facial motor nucleus) corresponds to the classically defined Bötzinger region (Alheid et al., 2002). This region contained the expected mix of respiratory phasic neurons consisting mostly of expiratory augmenting or decrementing neurons with fewer inspiratory neurons. Each recorded neuron was subjected to the hypoxia protocol illustrated in Figure $1 A$. The neuron was first recorded under hypercapnic hyperoxia ( $10 \%$ end-expiratory $\mathrm{CO}_{2}, 90 \%$ inhaled $\mathrm{O}_{2}$ ), considered here as the baseline condition. Hypercapnia was used to approximate conditions present in the brainstem spinal cord preparation of the neonate where extracellular $\mathrm{pH}$ is reportedly 6.9 or less because of metabolic acidosis (Brockhaus et al., 1993). Following this control period, a mixture of $5 \% \mathrm{O}_{2}$ balanced with nitrogen enriched with the same percentage of $\mathrm{CO}_{2}$ as during the control period was administered on average for $85 \mathrm{~s}$ (range, 60-120 s) causing an approximately exponential decrease in inhaled oxygen tension (Fig. $1 A$ ). Based on the response of blood pressure (BP) and PND, the hypoxic response was divided into three phases, although the transformation of the PND was gradual throughout these phases. During phase 1, BP and PND amplitude increased, PND rate increased, and inspiration duration, Ti, decreased (Fig. 1C, Table 1). This phase corresponds to the time when the effects of peripheral chemoreceptor stimulation prevail. During phase 2, BP dropped abruptly and then stabilized, PND frequency slowed gradually, PND amplitude increased further, and Ti gradually narrowed (Fig. 1 A,D, Table 1). At the end of phase 2, the last three to nine (mean, 6.3) phrenic discharges developed typical gasp-like characteristics (very low frequency and high amplitude bursts with decrementing pattern) (Fig. $1 D$, Table 1). Gasping was only observed in 11 of the 14 rats. The unit recordings presented in this study were obtained exclusively from the 11 rats that displayed gasps. Phase 3, coincident with the beginning of reoxygenation and, presumably, the loss of peripheral chemoreceptor drive, was characterized by a rapid recovery of BP followed by an overshoot. 
During this phase, PND frequency gradually returned to control and the PND bursts gradually recovered from a narrow decremental gasp-like pattern to the normal eupneic pattern. Complete recovery of all parameters to baseline levels usually required $\sim 5 \mathrm{~min}$.

A population of respiratory-phasic neurons, also illustrated in Figure 1, consistently developed an intense preinspiratory discharge during the gasping phase and often also displayed a double burst discharge (preinspiratory/postinspiratory) during the early reoxygenation phase (beginning of phase 3 ). During the control period, these cells had an E-AUG discharge pattern and a very high-maximum firing frequency (Fig. $1 B 1$, Table 1). A brief postinspiratory rebound ( $0-2$ spikes per respiratory cycle) was seen in some of these neurons during hypercapnic hyperoxia (control phase) (Fig. $1 \mathrm{B1}$ ). Lowering $\mathrm{pCO}_{2}$ under continued hyperoxia revealed that the $\mathrm{CO}_{2}$ threshold of these E-AUG neurons was very close to that of the phrenic nerve discharge (results not illustrated). Specifically, when inspiratory $\mathrm{CO}_{2}$ was slowly reduced, most of these cells stopped discharging just before the phrenic nerve, but a minority had a low level of tonic discharge below PND threshold, which disappeared with only slight $(0.1-0.2 \%)$ further reductions in $\mathrm{pCO}_{2}$. During phase 1 of hypoxia, the E-AUG neurons fired even more intensely and earlier during the expiration phase (Fig. 1C, Table 1). During phase 2, these neurons discharged later during the prolonged expiratory phase and finally adopted an intense preinspiratory burst pattern at the time when PND had a clearly gasp-like characteristic (Fig. 1D1-D2; Table 1). During phase 3 (the early phase of reoxygenation), these cells kept their distinctly pre-I discharge and frequently (14 of 31 neurons) also displayed a rebound discharge centered at the end of the PND giving them a pfRGlike double-burst discharge bracketing phrenic nerve activity (Fig. 1E1-E2).

A third of the E-AUG neurons that developed a pre-I pattern during gasping also had ectopic bursts during this period [i.e., bursts that occurred between two phrenic nerve discharges (10 of 31 neurons)] (Fig. $1 F$ ).
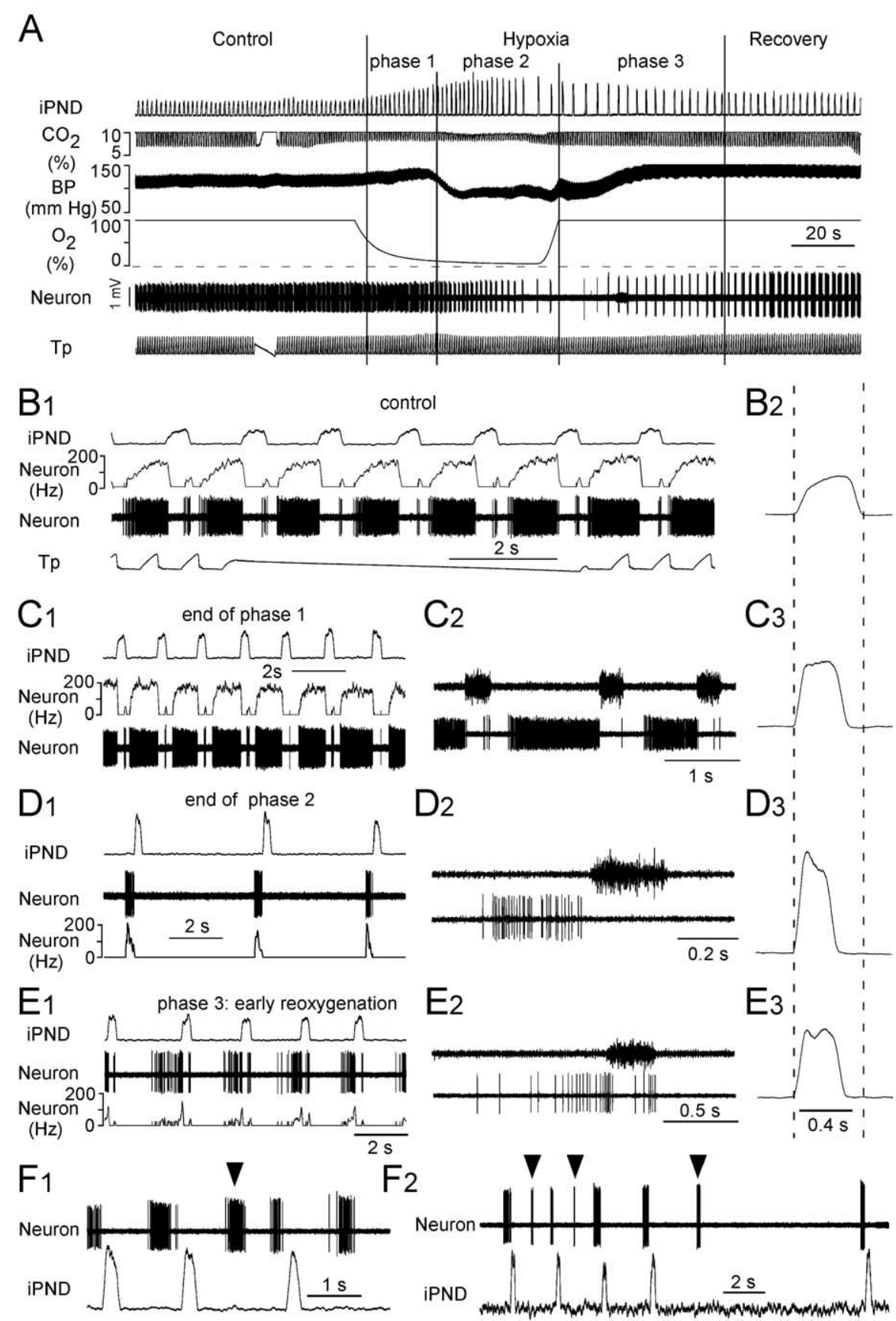

Figure 1. Bötzinger E-AUG neurons become pre-I under hypoxia. $\boldsymbol{A}$, Experimental design. The three phases of the hypoxic response are indicated by vertical bars. The interruption in the tracheal pressure trace $(\mathrm{Tp})$ and the end-expiratory $\mathrm{CO}_{2}$ trace $\left(\mathrm{CO}_{2}\right)$ identifies a brief period during which the respirator was switched off. $\boldsymbol{B}$, Discharge pattern of the neuron shown in $\boldsymbol{A}$ during the control period. Note the E-AUG pattern and the small rebound at the end of inspiration. B2, Computer average of iPND during the control period; note the incremental pattern. C1, Same cell during the first phase of hypoxia. The cell discharges earlier during expiration and rapidly reaches a plateau discharge. (2, PND and unit at expanded scale. C3, Averaged iPND. Note the shortened but still slightly incrementing pattern. D1, Cell during late phase 2 (gasping). Note the brief but intense preinspiratory bursts. D2, Expanded scale view of the PND and the preinspiratory discharge of the cell. D3, Averaged iPND (average of 5 phrenic bursts). The burst is short and strongly decrementing. E1, Same cell during phase 3 . Note the paired pre-I and post-I bursts. E2, Expanded scale view of PND and the double discharge of the cell during phase 3. E3, Averaged iPND during phase 3 (average of 8 bursts). F1, F2, Two examples of pre-I neurons with ectopic bursting during late phase 2 .
Location and transmitter of the E-AUG neurons with preinspiratory discharge

Twelve E-AUG neurons with pre-I discharge under hypoxia were labeled with biotinamide in five rats (Fig. 2). These cells had large numbers of axonal varicosities in the ipsilateral ven- tral respiratory column and possessed an axonal branch that ascended dorsomedially in a slightly rostral direction, crossed the midline, and could not be followed any further (results not illustrated). In three of these rats, biotinamide and GLYT2 mRNA were detected simultaneously. Each biotinamide- 
Table 1. Effects of hypoxia on Bötzinger E-AUG neurons

\begin{tabular}{|c|c|c|c|c|c|c|c|c|c|}
\hline & \multicolumn{2}{|l|}{ Rest } & \multicolumn{3}{|l|}{ Phase 1} & \multicolumn{3}{|c|}{ End of phase 2} & \multirow[b]{2}{*}{$n$} \\
\hline & $\mathrm{m}$ & SE & $\mathrm{m}$ & SE & Fold change & $\mathrm{m}$ & SE & Fold change & \\
\hline iPND amplitude (a.u.) & $1^{a}$ & & $1.52^{b}$ & 0.07 & 1.52 & $2.13^{c}$ & 0.11 & 2.13 & 31 \\
\hline PND frequency $\left(\min ^{-1}\right)$ & $45.9^{a}$ & 2.4 & $51.4^{b}$ & 2.7 & 1.12 & $21.3^{c}$ & 1.05 & 0.47 & 31 \\
\hline $\mathrm{Ti}(s)$ & $0.55^{a}$ & 0.01 & $0.45^{b}$ & 0.01 & 0.82 & $0.33^{c}$ & 0.01 & 0.61 & 31 \\
\hline $\mathrm{Te}(\mathrm{s})$ & $0.84^{a}$ & 0.05 & $0.82^{a}$ & 0.05 & 0.98 & $2.71^{b}$ & 0.17 & 3.23 & 31 \\
\hline E-AUG spikes/burst & $61.8^{a}$ & 5.0 & $96.0^{b}$ & 5.8 & 1.55 & $47.7^{c}$ & 4.4 & 0.77 & 31 \\
\hline E-AUG burst duration (s) & $0.74^{a}$ & 0.04 & $0.75^{a}$ & 0.05 & 1.01 & $0.37^{b}$ & 0.01 & 0.49 & 31 \\
\hline
\end{tabular}

Within each row, means with different superscript letters are significantly different at $p<0.05$ (repeated measures ANOVA). Means with the same letters are not statistically different. a.u., Arbitrary units.
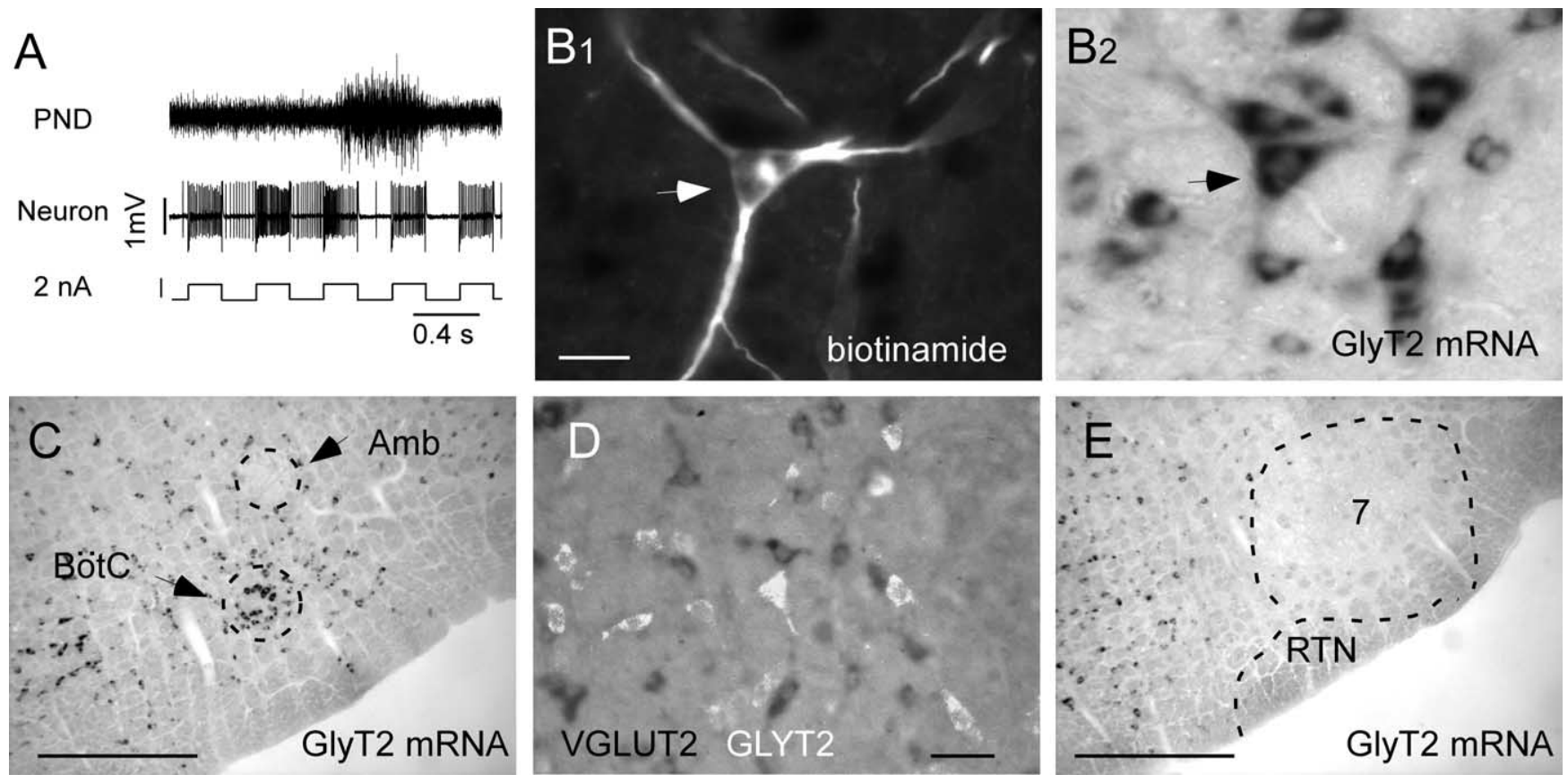

Figure 2. Phenotype of the pre-I neurons. $\boldsymbol{A}$, Activation of a pre-I cell by extracellular application of positive current causing the neuron to take up biotinamide. $\boldsymbol{B}$, Example of a biotinamidelabeled pre-I neuron containing GLYT2 mRNA (arrow). B1 and $\boldsymbol{B} 2$ represent the same field seen either under fluorescence (B1, red; $\mathbf{C y}$-3) or under bright-field illumination (B2). $\boldsymbol{C}$, Low-power photomicrograph of the ventrolateral medulla $100 \mu \mathrm{m}$ behind the facial motor nucleus showing the cluster of large glycinergic neurons where $E-A U G /$ pre-I cells congregate (BötC). $D$, Double in situ hybridization showing that GLYT2 mRNA (white, originally Cy3 fluorescence) and VGLUT2 mRNA (dark cells) are present in different cells within the Bötzinger region. $\boldsymbol{E}$, Low-power photograph of the ventrolateral medulla at the level of the caudal end of the facial motor nucleus (7) showing that the retrotrapezoid nucleus (RTN) does not contain glycinergic neurons [coronal plane, - 11.5 mm after Paxinos and Watson (1998)]. Scale bars: (in B1) B1, B2, $30 \mu \mathrm{m} ; \boldsymbol{C}, \boldsymbol{E}, 0.5 \mathrm{~mm} ; \boldsymbol{D}, 50 \mu \mathrm{m}$. Amb, Nucleus ambiguus.

labeled cell recovered from these three brains $(n=7)$ contained high levels of GLYT2 mRNA, indicating that the E-AUG neurons are glycinergic (Fig. $2 \mathrm{~B}$ ). These generally multipolar and relatively large cells form an identifiable cluster of intensely GLYT2-mRNA-positive neurons located halfway between the compact nucleus ambiguus and the ventral medullary surface (Fig. 2C). Double in situ hybridization for GLYT2 and VGLUT2 mRNA revealed complete separation between these markers within the region of interest. In contrast, the RTN contained no glycinergic neurons (Fig. 2E). Figure $3 A$ shows the location of the 12 biotinamide-labeled E-AUG/pre-I neurons, seven of which (filled circles) were tested for the presence of GLYT2 mRNA and found to be positive for this marker. Figure $3 B$ depicts the location of all the E-AUG/pre-I neurons recorded $(n=31)$ as determined by their electrophysiological coordinates relative to the facial motor nucleus. The location of RTN chemoreceptors recorded in the present study is also plotted using the same coordinates. Only 14 of these RTN neurons were subjected to the hypoxia protocol. The rest were recorded in the course of unrelated experiments and are reported here to give a more accurate representation of their spread relative to the E-AUG cells. E-AUG/pre-I neurons and RTN cells formed two distinct albeit neighboring clusters.

\section{Effect of hypoxia on other types of Bötzinger region respiratory-phasic neurons}

Inspiratory neurons were usually found slightly dorsal to the E-AUG neurons. These cells $(n=7)$ remained strictly inspiratory at every phase of the hypoxic challenge, regardless of the change in shape and frequency of the PND. During late phase 2, their activity stopped exactly at the same time as that of the phrenic nerve, and they resumed firing also exactly on a par with the PND during phase 3 (results not illustrated).

Expiratory-decrementing (E-DEC) neurons were commonly encountered in the immediate vicinity of the E-AUG neurons. Two types could be distinguished on the basis of their response to hypoxia. The first and more interesting type $(n=6)$ discharged in a manner that appeared to be complementary to that of the E-AUG neurons regardless of the phase of hypoxia (Fig. 4 A, B1$B 4)$. During phase 1 of hypoxia, the burst duration of these cells tended to decrease (Fig. 4, Table 2), whereas that of E-AUG neu- 
Table 2. Effects of hypoxia on Bötzinger E-DEC neurons

\begin{tabular}{|c|c|c|c|c|c|c|c|c|c|}
\hline & \multicolumn{2}{|l|}{ Rest } & \multicolumn{3}{|l|}{ Phase 1} & \multicolumn{3}{|c|}{ End of phase 2} & \multirow[b]{2}{*}{$n$} \\
\hline & $\mathrm{m}$ & SE & $\mathrm{m}$ & SE & Fold change & $\mathrm{m}$ & SE & Fold change & \\
\hline PND frequency $\left(\min ^{-1}\right)$ & $38.5^{a}$ & 2.2 & $42.4^{a}$ & 3.1 & 1.10 & $27.4^{b}$ & 2.0 & 0.71 & 6 \\
\hline $\mathrm{Ti}(\mathrm{s})$ & $0.51^{a}$ & 0.04 & $0.44^{b}$ & 0.03 & 0.85 & $0.27^{c}$ & 0.01 & 0.52 & 6 \\
\hline $\mathrm{Te}(\mathrm{s})$ & $1.07^{a}$ & 0.09 & $1.01^{a}$ & 0.09 & 0.95 & $1.72^{b}$ & 0.20 & 1.61 & 6 \\
\hline E-DEC spikes/burst & $23.4^{a}$ & 4.2 & $26.5^{a}$ & 7.3 & 1.14 & $47.8^{b}$ & 7.1 & 2.05 & 6 \\
\hline $\mathrm{E}-\mathrm{DEC}$ burst duration (s) & $0.63^{a}$ & 0.06 & $0.52^{a}$ & 0.11 & 0.79 & $1.28^{b}$ & 0.24 & 2.03 & 6 \\
\hline
\end{tabular}

Within each row, means with different superscript letters are significantly different at $p<0.05$ (repeated-measures ANOVA). Means with the same letters are not statistically different.

A

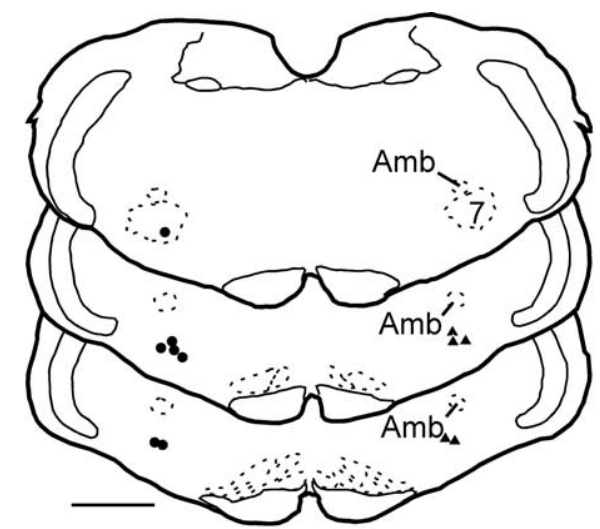

B

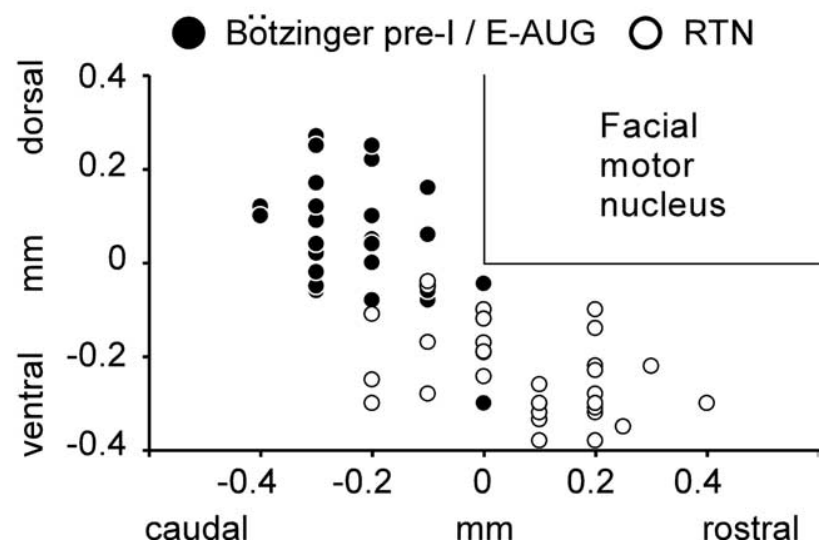

Figure 3. Relative location of pre-I and RTN neurons. $\boldsymbol{A}$, Computer-assisted mapping of the location of 12 biotinamide-labeled E-AUG/pre-I neurons. Filled circles indicate the seven cells that were tested for GLYT2 mRNA and found positive for this marker. Triangles on the right side of the sections show the other five biotinamide-labeled E-AUG/pre-I cells that were not tested for GLYT2. Scale bar, $1 \mathrm{~mm}$. B, Location of all pre-I and RTN neurons recorded. The positions of the cells are indicated by their stereotaxic coordinates in relation to the bottom and caudal end of the facial motor nucleus. These landmarks were identified electrophysiologically in each rat by means of antidromic field potentials. Amb, Nucleus ambiguus.

rons increased (Fig. 1). During the gasping phase (phase 2), the activity of these neurons increased markedly (Fig. 4, Table 2). Specifically, their discharge was maintained at a high rate throughout the prolonged expiratory phase and stopped $440 \pm$ $204 \mathrm{~ms}$ before the next phrenic gasp (Fig. 4 B3). Thus, during the gasping phase, these neurons stopped discharging around the time when the E-AUG neurons developed their preinspiratory burst. E-DEC neurons displayed a protracted period of tonic decrementing activity after the last gasp (7.2 $\pm 1.6 \mathrm{~s}$; range, $2.8-12)$ before becoming silent. During the recovery phase, E-DEC neurons resumed their high level of tonic firing throughout most of the prolonged expiratory phase. Their discharge was still absent during the phrenic burst and was weakest during the periods immediately preceding PND during which the pre-I cells discharged briskly (Fig. 4B4).

The rest of the E-DEC neurons $(n=7)$ discharged more robustly and longer during hypoxia phase 1 than during the control phase. The activity of these cells decreased steeply toward the end of hypoxia phase 2 , and they generally became silent during the gasps.

\section{Effect of hypoxia on RTN chemoreceptors and on blood pressure-regulating neurons}

As defined previously, RTN neurons were silent at low levels of end-expiratory $\mathrm{CO}_{2}$ and had a $\mathrm{CO}_{2}$ threshold below that of the $\mathrm{PND}$ and of any respiratory-phasic neuron encountered in the rostral VRC $\left(3.7-4.5 \% \mathrm{CO}_{2}\right)$. These cells ( $n=15$ in 7 rats) were vigorously activated at higher levels of $\mathrm{CO}_{2}$ (Fig. 5A1), and, under hyperoxia, they displayed a weak respiratory modulation up to $7-8 \%$ end-expiratory $\mathrm{CO}_{2}$ that intensified with more severe hypercapnia (Fig. 5A2). These cells were encountered deeper (300 $\mu \mathrm{m}$ on average) and more rostral in the VRC than the E-AUG neurons (Fig. $3 B$ ). Most of them were located under the caudal end of the facial motor nucleus in a region where respiratoryphasic neurons, including E-AUG cells, were generally absent. During the control period $\left(90 \% \mathrm{O}_{2}, 10 \% \mathrm{CO}_{2}\right)$, the respiratory rhythm of RTN neurons was always phase-spanning with discharge probability minima coinciding with postinspiration with an occasional early inspiratory dip as described previously (Guyenet et al., 2005a) (Fig. 5A2). During hypoxia phase 1, RTN neurons were vigorously activated, presumably because of their inputs from peripheral chemoreceptors (Takakura et al., 2006), and they developed a stronger postinspiratory inhibition. These cells remained active throughout phase 2 of hypoxia with a downward trend in discharge rate as hypoxia progressed (Fig. 5A1,A2,B). During phase 2, up to and including the gasping period, the cells were strongly respiratory modulated with minima during postinspiration and maxima during early inspiration (Fig. 5A2). After the last gasp, the cells resumed their tonic discharge pattern (Fig. $5 A 2$ ). The cells were further inhibited during the first few seconds of reoxygenation, and they resumed a high level of discharge thereafter. In summary, at no time during the hypoxic challenge did any of these cells develop a pfRG-like pre-I discharge pattern. Furthermore, their respiratory modulation, although of variable magnitude during the successive phases of hypoxia, had the same pattern throughout (Fig. 5A2).

BP-regulating neurons $(n=6)$ were identified as neurons with discharge probability that was strongly modulated by the arterial pulse and that were only modestly inhibited (0-30\%) by lowering end-expiratory $\mathrm{CO}_{2}$ from 10 to $4 \%$ (Brown and Guyenet, 1985; Mulkey et al., 2004). These cells are already known to be activated during all phases of a hypoxic or ischemic challenge because of their excitatory inputs from peripheral chemoreceptors and their intrinsic depolarization in response to brain hypoxia (Sun and Reis, 1994; Sun, 1996). The six pulse-synchronous 
A
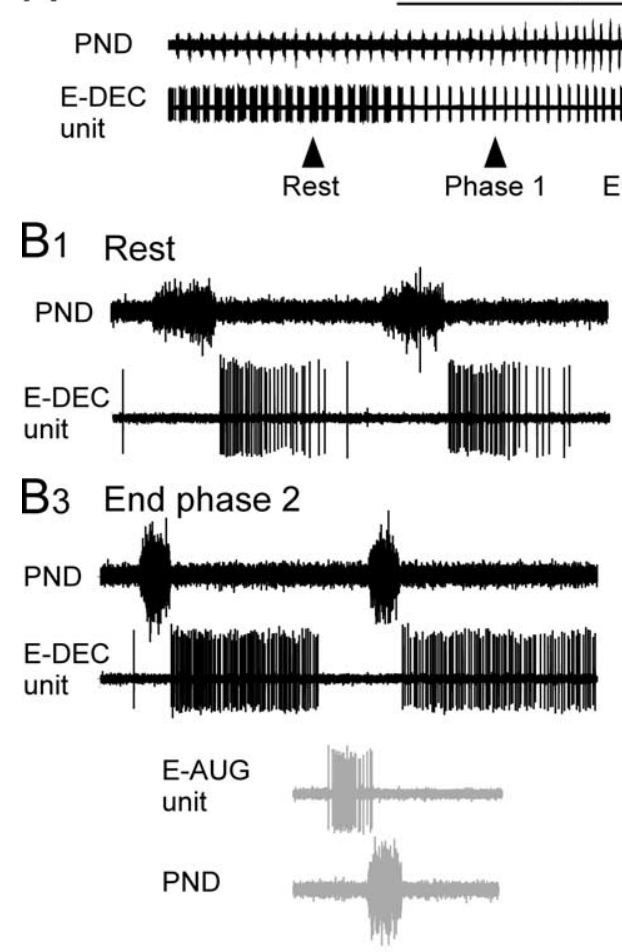

hypoxia

MIIIIII

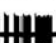

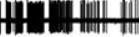

$\Delta$

End phase 2
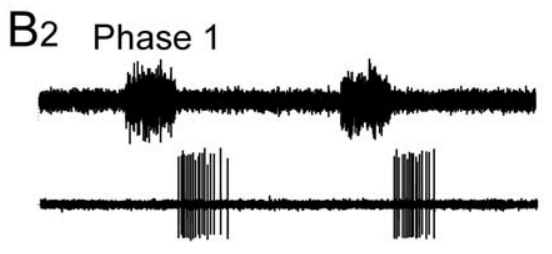

B4 Early reoxygenation

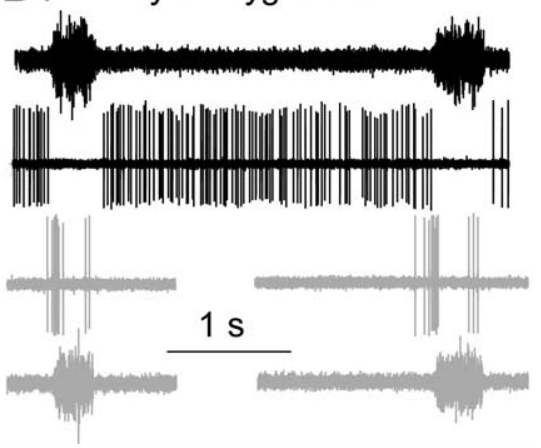

Figure 4. Discharge of a Bötzinger E-DEC neuron during hypoxia. $A$, Effect of hypoxia on an E-DEC neuron located in the Bötzinger region of the ventral respiratory column next to the E-AUG cells. B1-B4, Excerpts from the recording shown in $\boldsymbol{A}$. B1, Pattern at rest. $\boldsymbol{B 2}$, Pattern during phase 1 (early phase of hypoxia). Note the reduced duration and intensity of the discharge of the cell. B3, Pattern at the end of phase 2 (gasping). Burst duration and intensity of the E-DEC cell reincreased markedly, and the cell stopped discharging $390 \mathrm{~ms}$ before the onset of the next inspiration (PND). The bottom two traces (gray) illustrate the discharge of a neighboring Bötzinger E-AUG neuron recorded at the end of phase 2 during a previous hypoxia trial in the same animal. Trace alignment was done using the phrenic nerve discharge as reference. Note the complementarity of the discharges of the E-AUG and E-DEC cells. B4, Discharge pattern of the same two neurons during phase 3 (early reoxygenation). The E-DEC neuron had a prolonged discharge lasting throughout the expiratory phase, whereas the E-AUG cell (in gray) displays the familiar twice-bursting peri-inspiratory discharge pattern. Calibration: (in B4) $1 \mathrm{~s}$ (applies to all the traces in B1-B4).

neurons recorded presently were activated during phase 1 and phase 2 of the hypoxic challenge and did not develop a pre-I discharge either during gasping or during the early recovery period. As described previously, some of these cells were located medial to the RTN neurons and at about the same depth (Mulkey et al., 2004), but most were found slightly below the E-AUG neurons (Kanjhan et al., 1995).

Expiratory-augmenting bulbospinal neurons of the caudal VRG become preinspiratory during hypercapnic hypoxia

The caudal part of the ventral respiratory column contains the bulk of the excitatory bulbospinal premotor neurons that drive abdominal and other expiratory muscles (Ballantyne and Richter, 1986; Arita et al., 1987; Iscoe, 1998, Alheid et al., 2002). These neurons have no supraspinal axonal collaterals and no known function other than to drive expiratory motor neurons (Ballantyne and Richter, 1986; Arita et al., 1987; Iscoe, 1998; Ezure et al., 2003b). Their activity can therefore be used as an index of the expiratory motor output of the central respiratory pattern generator. The next experiments were designed to test whether these expiratory-augmenting neurons were active in our preparation and whether, like the E-AUG neurons of the Bötzinger region, these cells develop a preinspiratory or peri-inspiratory discharge pattern under hypercapnic hypoxia (Fig. 6A). The cVRG was explored under hyperoxic and hypercapnic conditions (8-9\%
$\mathrm{CO}_{2}$ in pure oxygen), and expiratory neurons were then tested for their response to hypercapnic hypoxia. The region shown by the square black box in Figure $6 \mathrm{D}$ contained an abundance of E-AUG neurons that were all (27 of 27) bulbospinal as expected (Fig. 6B1-B4, C1) (see Materials and Methods for details) (Ballantyne and Richter, 1986).

Recordings from 10 such bulbospinal E-AUG neurons (four rats) were kept throughout our standard hypercapnic hypoxia protocol $(9-10 \%$ end-expiratory $\mathrm{CO}_{2}$, hypoxic episode of 60-80 s duration). During phase 1 , the activity of all these neurons increased greatly, and they started discharging earlier during the expiratory phase (Fig. 6, compare $B 2$ and $B 1$ ). These changes are the expected effects of peripheral chemoreceptor stimulation. When gasping occurred, three neurons from two rats produced a brief but intense burst of activity immediately before the phrenic nerve discharge (Fig. 6C2). This activity was identical to that observed in many Bötzinger neurons (compare Figs. $1 D 1$ and $6 C 2$ ). One cell also displayed an ectopic burst (i.e., a burst that was not followed by a phrenic discharge) (Fig. 6C2). During the early recovery phase, the cVRG expiratory neurons typically ( 8 of 10 neurons; three rats) displayed a double burst (preinspiratory and postinspiratory) before gradually recovering their normal E-AUG pattern (Fig. 6B3). This doubledischarge pattern was very reminiscent of the firing mode of the Bötzinger E-AUG neurons during the same phase of the hypoxia protocol (compare Figs. $1 E$ and 6B3).

\section{Discussion}

Pre-I activity has been observed previously only in the Suzue preparation and in neonate rats treated with fentanyl and ketamine. Here, we show that a similar pattern is elicited in anesthetized adult rats by hypoxic hypercapnia. Retroambigual expiratory premotor neurons and Bötzinger E-AUG glycinergic neurons developed the pre-I pattern under hypoxia, but the RTN chemoreceptors did not. We propose that the pfRG (Onimaru and Homma, 2003) could be a heterogeneous collection of E-AUG neurons that develop a pre-I firing mode because of a general reconfiguration of the respiratory network.

\section{Pre-I pattern and respiratory network reconfiguration}

Severe hypoxia in vivo produces brief, low-frequency, and highamplitude phrenic bursts with a decremental pattern (St-John, 1998; Paton et al., 2006). For unknown reasons, the phrenic discharge of the Suzue preparation has somewhat similar characteristics (Brockhaus et al., 1993; Dutschmann et al., 2000; Taccola et al., 2007). The breathing network of adult rats under severe hypoxia in vivo and the Suzue preparation exhibit a second unusual feature namely a lumbar expiratory outflow characterized by twin preinspiratory and postinspiratory discharges (Taccola et al., 2007; our results). These similarities suggest that the central 
respiratory network of the Suzue preparation and that of the adult rat under hypoxia could be similarly reconfigured despite differences in the age of the animal and the factors that trigger the reconfiguration (hypoxia, hypotension, anesthesia in vivo vs anoxic core, acidic parenchyma, low temperature and total sensory deafferentation in vitro). This interpretation is supported by the fact that pre-I activity, which is normally absent in the adult, is observed under both conditions in the Bötzinger region of the ventral respiratory column (Ballanyi et al., 1999; Onimaru and Homma, 2003; our results).

An analogous network reconfiguration may also be caused by administration of ketamine and fentanyl to intact juvenile rats, because this treatment also produces a pre-I/post-I discharge in abdominal expiratory motor neurons (Janczewski and Feldman, 2006).

\section{Bötzinger E-AUG neurons as pre-I neurons}

The Bötzinger E-AUG inhibitory neurons were identified presently by their discharge characteristics (Bryant et al., 1993; Kanjhan et al., 1995; Ezure et al., 2003b) and the fact that they contained GLYT2 mRNA, a diagnostic marker of glycinergic neurons (Schreihofer et al., 1999; Ezure et al., 2003a). Additional congruent evidence included the fact that these E-AUG/pre-I cells had large numbers of axonal collaterals within more caudal regions of the ipsilateral VRC and had an axonal branch crossing the midline within the dorsal tegmentum at midfacial level (Bryant et al., 1993; Ezure et al., 2003b). These anatomical features are consistent with the fact that Bötzinger E-AUG neurons monosynaptically inhibit many types of ipsilateral and contralateral dorsal and ventral respiratory group neurons via chloride-dependent IPSPs (Tian et al., 1998; Tian et al., 1999) (for review, see Long and Duffin, 1986). The absence of VGLUT2 in glycinergic Bötzinger E-AUG neurons (present study) further reduces the probability that these cells might also be excitatory and could be antecedent to abdominal premotor neurons.

In adult cats, the Bötzinger E-AUG neurons were not found to adopt a pre-I pattern under hypoxia (Richter et al., 1991; England et al., 1995). The discrepancy could be species- or anestheticrelated or a result of more severe hypercapnic hypoxia in our case.

The present observations suggest that the Bötzinger E-AUG inhibitory neurons could be among the neurons previously classified as pfRG in the Suzue preparation. Consistent with this interpretation, neonate pre-I neurons are commonly recorded in a retrofacial region that matches the Bötzinger area of the adult (Janczewski et al., 2002; Onimaru et al., 2006a; Barnes et al., 2007). Furthermore, like the inhibitory Bötzinger E-AUG neurons (Long and Duffin, 1986; Bryant et al., 1993; Ezure et al., 2003b), these particular pre-I neurons innervate the ipsilateral retroambigual region (Janczewski et al., 2002).

In apparent contradiction with our results, excitatory pre-I neu- rons have also been described in the Suzue preparation (Onimaru et al., 1992; Janczewski et al., 2002). Because evidence for excitatory Bötzinger E-AUG neurons is marginal at best (Jiang and Lipski, 1990), the excitatory pre-I cells postulated by Onimaru could be located outside the Bötzinger region.

No evidence that RTN chemoreceptors are pre-I neurons RTN neurons, as we define them (Mulkey et al., 2004; Guyenet et al., 2005b; Stornetta et al., 2006), did not display a pre-I pattern under hypoxia, contrary to the Bötzinger neurons and the expiratory premotor neurons of the retroambigual region. A lone neuron recorded in the RTN region of the cat was reported to have a double burst discharge (Connelly et al., 1990), but this unidentified neuron resembled a Bötzinger E-AUG neuron with postinspiratory rebound (Fig. 1B1).

Although close, RTN neurons and E-AUG/pre-I neurons clustered in two distinct regions; RTN chemoreceptors were located more rostrally and much closer to the ventral medullary surface than the E-AUG neurons. RTN chemoreceptors and E-AUG/pre-I neurons also have very different markers. RTN neurons are glutamatergic and express the transcription factor Phox2b (Stornetta et al., 2006), whereas the pre-I/E-AUG neu- 


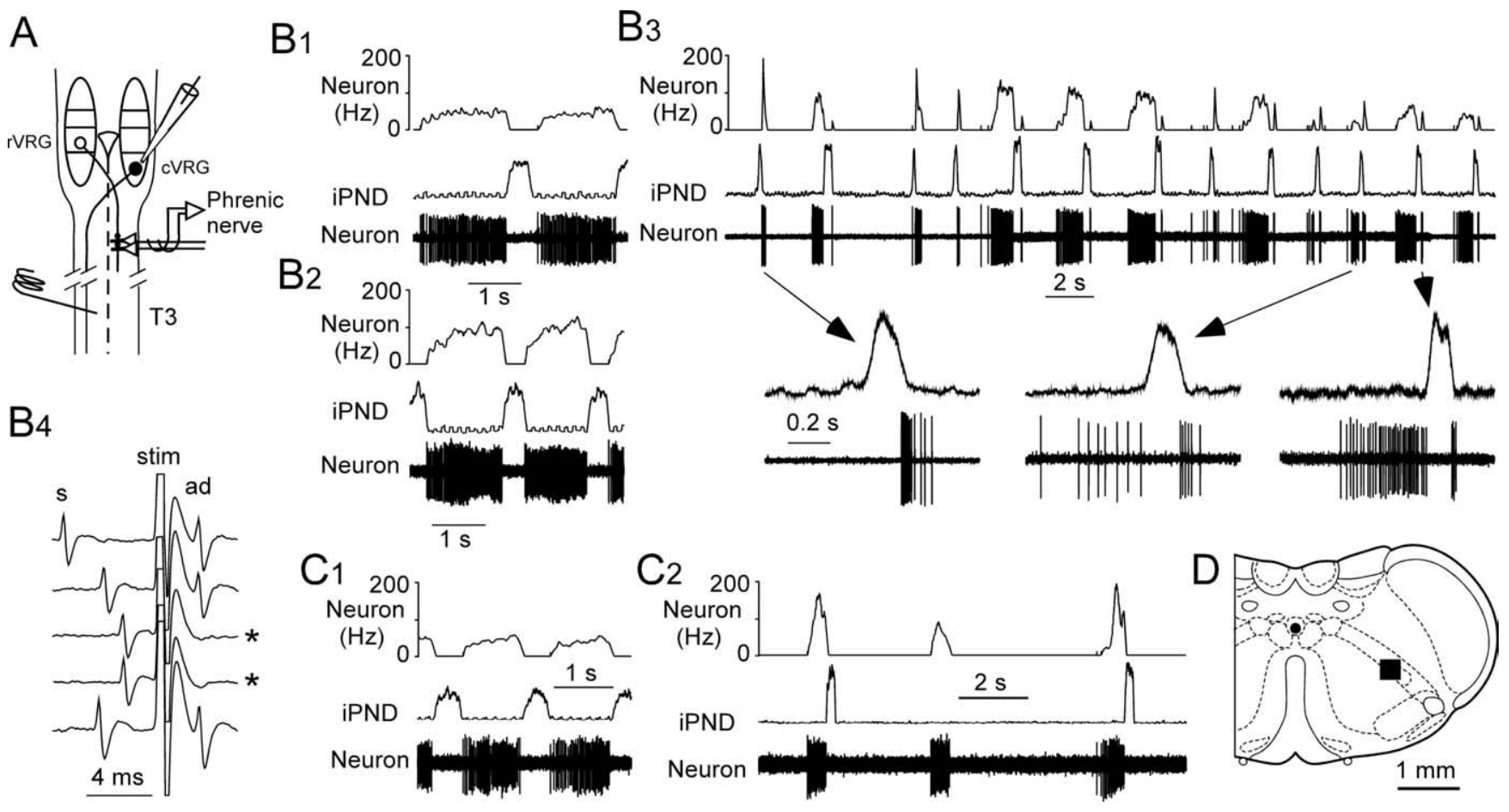

Figure 6. Effect of hypoxia on bulbospinal expiratory neurons of nucleus retroambiguus. $A$, Experimental design. rVRG, Rostral ventral respiratory group; cVRG is also known as retroambiguus nucleus. B1, Discharge pattern of a bulbospinal expiratory neuron during the control period $\left(9 \% \mathrm{CO}_{2}\right.$, balance oxygen). B2, Same neuron at the beginning of the hypoxic stimulus (defined as phase 1 in Fig. 1). B3, Same neuron during phase 3 of the hypoxic stimulus. Note the double preinspiratory and postinspiratory discharge. B4, Same neuron showing antidromic activation (ad) $2.4 \mathrm{~ms}$ after spinal cord stimulation (stim), except on the third and fourth sweeps (asterisks) when collision between a spontaneous spike (s) and the antidromic spike occurred. C1, Different bulbospinal expiratory neuron during the control period. C2, Same neuron during end of phase 2. Note the intense but brief bursts preceding the phrenic discharge and the ectopic middle burst. $\boldsymbol{D}$, The black square represents the location of the 27 bulbospinal expiratory neurons. This site was determined by plotting the electrophysiological coordinates of the cells on the appropriate section of the Paxinos atlas ( $0.6 \mathrm{~mm}$ caudal to the area postrema; bregma $-14.6 \mathrm{~mm}$ ).

rons are glycinergic and lack both Phox $2 b$ (Schreihofer et al., 1999; Stornetta et al., 2006) and VGLUT2 (present study).

In a tilted version of the Suzue preparation, the RTN region apparently lacks neurons that generate respiratory synchronous calcium signals, contrary to the overlying facial motor nucleus or more caudal Bötzinger region (Barnes et al., 2007). This evidence suggests that RTN neurons may not burst in this preparation, as is also the case in vivo (Guyenet et al., 2005a).

In conclusion, RTN chemoreceptors do not become pre-I under hypoxia in vivo. This evidence suggests that RTN chemoreceptors may not belong to the neuronal population defined as pfRG in the Suzue preparation, but this possibility is not eliminated by our data. This issue can only be settled by testing whether some of the neonatal "parafacial" pre-I neurons express the biochemical markers that define RTN chemoreceptors (Stornetta et al., 2006).

\section{Mechanism underlying the preinspiratory pattern of Bötzinger E-AUG neurons}

The discharge of Bötzinger E-AUG neurons, like that of retroambigual bulbospinal premotor neurons, presumably depends on tonic excitatory drives originating from chemoreceptors plus phasic inhibitory inputs from inspiratory and E-DEC neurons (Bainton and Kirkwood, 1979; Ballantyne and Richter, 1986; Ezure, 1990; Iscoe, 1998). Three reasons suggest that the brief but intense preinspiratory discharge of the E-AUG Bötzinger neurons could be attributable to their delayed release from an abnormally prolonged early expiratory inhibition. Bötzinger E-DEC and E-AUG neurons are mutually inhibitory (Bryant et al., 1993; Ezure et al., 2003a; Rybak et al., 2004). A subset of Bötzinger
E-DEC neurons becomes E-throughout during hypoxia in vivo (Fig. 4). The Suzue preparation lacks E-DEC neurons but, appropriately, contains many E-throughout cells (Ballanyi et al., 1999).

Our results do not clarify why hypoxia would shift the reciprocal inhibition between Bötzinger E-DEC and E-AUG neurons to the detriment of E-AUG cells. Speculatively, hypoxia could preferentially depress the excitability of the E-AUG cells or selectively reduce their ability to release glycine. Differential expression of adenosine receptors or ATP-dependent potassium conductances in E-DEC versus E-AUG cells could also be involved. The preinspiratory pattern induced by opiates could have a similar explanation (Guyenet et al., 2002; Janczewski and Feldman, 2006).

The rebound discharge of the Bötzinger neurons after inspiration is not explained by this mechanism. This rebound could be caused by hyperpolarization-induced inward currents reactivated by the strong inhibition to which the cells are subjected during early inspiration (Schwarzacher et al., 1991). Alternately, hypoxia may silence inspiratory-expiratory transition neurons, a pattern that, interestingly, seems to be also absent in the Suzue preparation (Ballanyi et al., 1999).

\section{What is the pfRG?}

Three types of pre-I neurons are now proven to have an E-AUG discharge under more physiological conditions in vivo, namely abdominal motor neurons (neonate), abdominal premotor neurons (neonate and adult) (Janczewski et al., 2002; Janczewski and Feldman, 2006; Taccola et al., 2007; our study) and the Bötzinger region neurons shown here to be glycinergic. This observation 
raises the possibility that the rest of the pre-I neurons could also derive from E-AUG neurons.

As mentioned above, the glycinergic Bötzinger neurons do not innervate abdominal premotor neurons; therefore, the notion that brainstem pre-I neurons are connected to each other in some form of semiautonomous oscillator related to expiration should be viewed with caution (Janczewski and Feldman, 2006). The discharge pattern of all E-AUG neurons seems to rely on similar mechanisms (inspiratory and postinspiratory inhibition and tonic drives). It is therefore not surprising that their discharge would be similarly altered (into the pre-I pattern) by conditions that broadly reconfigure the network responsible for generating the three-phase respiratory pattern present in more intact preparations (Long and Duffin, 1986; Rybak et al., 2004). This network, which prominently features the Bötzinger E-AUG and E-DEC cells (Rybak et al., 2004) is presumably driven by the pre-Bötzinger rhythm generator (Feldman and Del Negro, 2006) and is separated from pump and airway motor neurons by a least one interneuron (the premotor neurons). The pfRG neurons of the Suzue preparation (Onimaru et al., 2006b) are still incompletely characterized (i.e., the number of cell types, their transmitters, and their role(s) within the respiratory network are still uncertain). Some pfRG neurons could conceivably be subsets of facial motor neurons, because many such cells have an E-AUG discharge pattern under normal conditions (Bianchi et al., 1995), and the motor nucleus is active in the Suzue preparation (Onimaru et al., 2006b). Facial motor neurons are inactive under halothane anesthesia and would not have been identified in our experiments. Also, brainstem motor nuclei are typically surrounded by premotor cells (Brodal, 1981). By analogy with the abdominal expiratory outflow, some of the pre-I neurons located in the perifacial region could be facial expiratory premotor neurons.

The fact that the E-AUG/pre-I neurons have ectopic bursts during gasping (Figs. $1 F, 6 C 2$ ) suggests that portions of the central respiratory pattern generator keep oscillating during cycles when no phrenic outflow is being produced. This phenomenon is especially striking after treatment with ketamine and fentanyl (Janczewski and Feldman, 2006), and the recent study of Barnes et al. (2007) also shows that, in the Suzue preparation, large numbers of respiratory neurons, including many that are located within the rhythm-generating region of the pre-Bötzinger complex, continue discharging phasically during cycles that generate no phrenic discharge.

One argument supporting the existence of an independent respiratory rhythm generator situated rostral to the preBötzinger complex is that rhythmic facial nerve activity is still observed in thick coronal blocks of the rostral medulla that exclude the pre-Bötzinger complex (Onimaru et al., 2006a). However, these blocks apparently include a large portion of the Bötzinger region in addition to the RTN chemoreceptors. The reciprocal inhibition between E-AUG and E-DEC neurons (Rybak et al., 2004) combined with a tonic drive from RTN chemoreceptors to the Bötzinger complex may form the basis of a residual oscillating network that influences facial motor neurons in part via the projections of the E-AUG neurons to the lateral facial region (Ezure et al., 2003b).

Expiratory abdominal activity also requires a central chemoreceptor drive and the fact that a transection through the RTN eliminates abdominal expiratory activity (Janczewski and Feldman, 2006) may have more to do with the loss of the chemical drive from RTN or to the interruption of ponto-medullary con- nections than to the elimination of a parafacial oscillator specialized in generating the expiratory motor outflow.

In conclusion, under hypoxia in vivo, two types of E-AUG respiratory interneurons (Bötzinger glycinergic neurons and abdominal premotor neurons) adopt a firing mode reminiscent of the pre-I pattern found in the Suzue preparation. This similarity suggests that the pre-I neurons of the Suzue preparation could be a heterogeneous collection of E-AUG neurons with a pattern that is similarly reconfigured. The rostral pre-I neurons (pfRG) probably include the Bötzinger glycinergic neurons and may also include facial expiratory premotor and motor neurons. RTN chemoreceptors do not develop a pre-I pattern in vivo and are presumably not among the neurons defined as pfRG. A thorough neuroanatomical characterization of the various types of pre-I neurons present in the Suzue preparation will be required to test the validity of our predictions.

\section{References}

Alheid GF, Gray PA, Jiang MC, Feldman JL, McCrimmon DR (2002) Parvalbumin in respiratory neurons of the ventrolateral medulla of the adult rat. J Neurocytol 31:693-717.

Arita H, Kogo N, Koshiya N (1987) Morphological and physiological properties of caudal medullary expiratory neurons of the cat. Brain Res 401:258-266.

Bainton CR, Kirkwood PA (1979) The effect of carbon dioxide on the tonic and the rhythmic discharges of expiratory bulbospinal neurones. J Physiol (Lond) 296:291-314.

Ballantyne D, Richter DW (1986) The non-uniform character of expiratory synaptic activity in expiratory bulbospinal neurones of the cat. J Physiol (Lond) 370:433-456.

Ballanyi K, Onimaru H, Homma I (1999) Respiratory network function in the isolated brainstem-spinal cord of newborn rats. Prog Neurobiol 59:583-634.

Barnes BJ, Tuong CM, Mellen NM (2007) Functional imaging reveals respiratory network activity during hypoxic and opioid challenge in the neonate rat tilted sagittal slab preparation. J Neurophysiol 97:2283-2292.

Bianchi AL, Denavit-Saubie M, Champagnat J (1995) Central control of breathing in mammals: neuronal circuitry, membrane properties, and neurotransmitters. Physiol Rev 75:1-45.

Brockhaus J, Ballanyi K, Smith JC, Richter DW (1993) Microenvironment of respiratory neurons in the in vitro brainstem-spinal cord of neonatal rats. J Physiol (Lond) 462:421-445.

Brodal P (1981) Chapter 7: the cranial nerves. In: Neurological anatomy, pp 448-577. New York: Oxford UP.

Brown DL, Guyenet PG (1985) Electrophysiological study of cardiovascular neurons in the rostral ventrolateral medulla in rats. Circ Res 56:359-369.

Bryant TH, Yoshida S, deCastro D, Lipski J (1993) Expiratory neurons of the Botzinger complex in the rat: a morphological study following intracellular labeling with biocytin. J Comp Neurol 335:267-282.

Connelly CA, Ellenberger HH, Feldman JL (1990) Respiratory activity in retrotrapezoid nucleus in cat. Am J Physiol 258:L33-L44.

Dutschmann M, Wilson RJA, Paton JFR (2000) Respiratory activity in neonatal rats. Autonom Neurosci 84:19-29.

England SJ, Melton JE, Douse MA, Duffin J (1995) Activity of respiratory neurons during hypoxia in the chemodenervated cat. J Appl Physiol 78:856-861.

Ezure K (1990) Synaptic connections between medullary respiratory neurons and considerations on the genesis of respiratory rhythm. Prog Neurobiol 35:429-450.

Ezure K, Tanaka I, Kondo M (2003a) Glycine is used as a transmitter by decrementing expiratory neurons of the ventrolateral medulla in the rat. J Neurosci 23:8941-8948.

Ezure K, Tanaka I, Saito Y (2003b) Brainstem and spinal projections of augmenting expiratory neurons in the rat. Neurosci Res 45:41-51.

Feldman JL, Del Negro CA (2006) Looking for inspiration: new perspectives on respiratory rhythm. Nat Rev Neurosci 7:232-242.

Feldman JL, Mitchell GS, Nattie EE (2003) Breathing: rhythmicity, plasticity, chemosensitivity. Annu Rev Neurosci 26:239-266.

Guyenet PG, Stornetta RL, Schreihofer AM, Pelaez NM, Hayar A, Aicher S, 
Llewellyn-Smith IJ (2002) Opioid signalling in the rat rostral ventrolateral medulla. Clin Exp Pharmacol Physiol 29:238-242.

Guyenet PG, Mulkey DK, Stornetta RL, Bayliss DA (2005a) Regulation of ventral surface chemoreceptors by the central respiratory pattern generator. J Neurosci 25:8938-8947.

Guyenet PG, Stornetta RL, Bayliss DA, Mulkey DK (2005b) Retrotrapezoid nucleus: a litmus test for the identification of central chemoreceptors. Exp Physiol 90:247-253.

Iscoe S (1998) Control of abdominal muscles. Prog Neurobiol 56:433-506.

Janczewski WA, Feldman JL (2006) Distinct rhythm generators for inspiration and expiration in the juvenile rat. J Physiol (Lond) 570:407-420.

Janczewski WA, Onimaru H, Homma I, Feldman JL (2002) Opioidresistant respiratory pathway from the preinspiratory neurones to abdominal muscles: in vivo and in vitro study in the newborn rat. J Physiol (Lond) 545:1017-1026.

Jiang C, Lipski J (1990) Extensive monosynaptic inhibition of ventral respiratory group neurons by augmenting neurons in the Botzinger complex in the cat. Exp Brain Res 81:639-648.

Kanjhan R, Lipski J, Kruszewska B, Rong WF (1995) A comparative study of pre-sympathetic and Botzinger neurons in the rostral ventrolateral medulla (RVLM) of the rat. Brain Res 699:19-32.

Long S, Duffin J (1986) The neuronal determinants of respiratory rhythm. Prog Neurobiol 27:101-182.

Mellen NM, Janczewski WA, Bocchiaro CM, Feldman JL (2003) Opioidinduced quantal slowing reveals dual networks for respiratory rhythm generation. Neuron 37:821-826.

Moreira TS, Takakura AC, Colombari E, West GH, Guyenet PG (2007) Inhibitory input from slowly adapting lung stretch receptors to retrotrapezoid nucleus chemoreceptors. J Physiol (Lond) 580:285-300.

Mulkey DK, Stornetta RL, Weston MC, Simmons JR, Parker A, Bayliss DA, Guyenet PG (2004) Respiratory control by ventral surface chemoreceptor neurons in rats. Nat Neurosci 7:1360-1369.

Nattie E, Li A (2000) Muscimol dialysis in the retrotrapezoid nucleus region inhibits breathing in the awake rat. J Appl Physiol 89:153-162.

Onimaru H, Homma I (2003) A novel functional neuron group for respiratory rhythm generation in the ventral medulla. J Neurosci 23:1478-1486.

Onimaru H, Arata A, Homma I (1989) Firing properties of respiratory rhythm generating neurons in the absence of synaptic transmission in rat medulla in vitro. Exp Brain Res 76:530-536.

Onimaru H, Homma I, Iwatsuki K (1992) Excitation of inspiratory neurons by preinspiratory neurons in rat medulla in vitro. Brain Res Bull 29:879-882.

Onimaru H, Kumagawa Y, Homma I (2006a) Respiration-related rhythmic activity in the rostral medulla of newborn rats. J Neurophysiol 96:55-61.

Onimaru H, Homma I, Feldman JL, Janczewski WA (2006b) Point:Counterpoint: the parafacial respiratory group ( $\mathrm{pFRG}$ )/pre-Botzinger complex (preBotC) is the primary site of respiratory rhythm generation in the mammal. J Appl Physiol 100:2094-2098.

Paton JF, Abdala AP, Koizumi H, Smith JC, St-John WM (2006) Respira- tory rhythm generation during gasping depends on persistent sodium current. Nat Neurosci 9:311-313.

Paxinos G, Watson C (1998) The rat brain in stereotaxic coordinates. San Diego: Academic

Richter DW, Bischoff A, Anders K, Bellingham M, Windhorst U (1991) Response of the medullary respiratory network of the cat to hypoxia. J Physiol (Lond) 443:231-256.

Rybak IA, Shevtsova NA, Paton JF, Dick TE, St-John WM, Morschel M, Dutschmann M (2004) Modeling the ponto-medullary respiratory network. Respir Physiol Neurobiol 143:307-319.

Schreihofer AM, Stornetta RL, Guyenet PG (1999) Evidence for glycinergic respiratory neurons: Bötzinger neurons express mRNA for glycinergic transporter 2. J Comp Neurol 407:583-597.

Schwarzacher SW, Wilhelm Z, Anders K, Richter DW (1991) The medullary respiratory network in the rat. J Physiol (Lond) 435:631-644.

St-John WM (1998) Neurogenesis of patterns of automatic ventilatory activity. Prog Neurobiol 56:97-117.

Stornetta RL, Sevigny CP, Guyenet PG (2003) Inspiratory augmenting bulbospinal neurons express both glutamatergic and enkephalinergic phenotypes. J Comp Neurol 455:113-124.

Stornetta RL, McQuiston TJ, Guyenet PG (2004) GABAergic and glycinergic presympathetic neurons of rat medulla oblongata identified by retrograde transport of pseudorabies virus and in situ hybridization. J Comp Neurol 479:257-270.

Stornetta RL, Moreira TS, Takakura AC, Kang BJ, Chang DA, West GH, Brunet JF, Mulkey DK, Bayliss DA, Guyenet PG (2006) Expression of Phox $2 \mathrm{~b}$ by brainstem neurons involved in chemosensory integration in the adult rat. J Neurosci 26:10305-10314.

Sun MK (1996) Pharmacology of reticulospinal vasomotor neurons in cardiovascular regulation. Pharmacol Rev 48:465-494.

Sun MK, Reis DJ (1994) Hypoxia-activated Ca2 + currents in pacemaker neurones of rat rostral ventrolateral medulla in vitro. J Physiol (Lond) 476:101-116.

Suzue T (1984) Respiratory rhythm generation in the in vitro brain stemspinal cord preparation of the neonatal rat. J Physiol (Lond) 354:173-183.

Taccola G, Secchia L, Ballanyi K (2007) Anoxic persistence of lumbar respiratory bursts and block of lumbar locomotion in newborn rat brainstem spinal cords. J Physiol (Lond) 585:507-524.

Takakura AC, Moreira TS, Colombari E, West GH, Stornetta RL, Guyenet PG (2006) Peripheral chemoreceptor inputs to retrotrapezoid nucleus (RTN) CO2-sensitive neurons in rats. J Physiol (Lond) 572:503-523.

Tian GF, Peever JH, Duffin J (1998) Botzinger-complex expiratory neurons monosynaptically inhibit phrenic motoneurons in the decerebrate rat. Exp Brain Res 122:149-156.

Tian GF, Peever JH, Duffin J (1999) Botzinger-complex, bulbospinal expiratory neurones monosynaptically inhibit ventral-group respiratory neurones in the decerebrate rat. Exp Brain Res 124:173-180.

Weston MC, Stornetta RL, Guyenet PG (2004) Glutamatergic neuronal projections from the marginal layer of the rostral ventral medulla to the respiratory centers in rats. J Comp Neurol 473:73-85. 